\title{
Dasyatispora levantinae gen. et sp. nov., a new microsporidian parasite from the common stingray Dasyatis pastinaca in the eastern Mediterranean
}

\author{
Ariel Diamant ${ }^{1, *}$, Menachem Goren $^{2}$, M. Baki Yokeş ${ }^{3}$, Bella S. Galil ${ }^{4}$, \\ Yaelle Klopman ${ }^{2}$, Dorothée Huchon ${ }^{2}$, Amir Szitenberg ${ }^{2}$, S. Ünsal Karhan ${ }^{5}$ \\ ${ }^{1}$ National Center for Mariculture, Israel Oceanographic and Limnological Research, P.O.B. 1212, Eilat 88112, Israel \\ ${ }^{2}$ Department of Zoology, George S. Wise Faculty of Life Sciences, Tel Aviv University, Tel Aviv 69978, Israel \\ ${ }^{3}$ Haliç University, Faculty of Arts \& Sciences, Department of Molecular Biology \& Genetics, Okmeydani, 34384 Istanbul, Turkey \\ ${ }^{4}$ National Institute of Oceanography, Israel Oceanographic and Limnological Research P.O.B. 8030, Haifa 31080, Israel \\ ${ }^{5}$ Division of Hydrobiology, Department of Biology, Faculty of Science, Istanbul University, 34134 Vezneciler, Istanbul, Turkey
}

\begin{abstract}
A new microsporidian infecting the Mediterranean common stingray Dasyatis pastinaca (Linnaeus, 1758) is described from Iskenderun Bay, Turkey. The parasite invades the disc muscles, producing slender, spindle-shaped subcutaneous swellings that develop into massive, elongated, tumor-like protuberances measuring up to $11 \times 4 \mathrm{~cm}$. Severity of the infection may vary from light (1 or 2 small lesions) to intense, with large parts of the dorsal surface covered with lumps and protrusions. These masses contained a yellowish-white caseous substance consisting of degraded host tissue and microsporidian sporophorous vesicles, which in turn contained developing sporonts, sporoblasts and spores. The ripe spore contained a uni-nucleate sporoplasm and large posterior vacuole, and measured 3.8-4.3 $\times 2.6-2.8 \mu \mathrm{m}$. Infection prevalence was $21 \%$ in a sample of 143 host individuals examined. All the infected stingray individuals were within the weight class of 300 to $800 \mathrm{~g}$ (200 to $305 \mathrm{~mm}$ disc width). Phylogenetic analyses of rDNA sequences indicate that this microsporidian belongs to the Pleistophoridae and clusters with species of the genera Ovipleistophora Pekkarinen, Lom \& Nilsen, 2002 and Heterosporis Schubert, 1969. However, the morphology, development and host differ distinctly from all reported species, including those belonging to these 2 genera, and it is thus assigned to a newly erected genus and named Dasyatispora levantinae gen. et sp. nov. This is the first record of a microsporidian infection in a batoid. It is also the first microsporidian species to be formally described from an elasmobranch.
\end{abstract}

KEY WORDS: Stingray $\cdot$ Microsporidian $\cdot$ Subcutaneous swellings $\cdot$ Tumor-like bulges $\cdot$ Pathology Eastern Mediterranean · Dasyatis pastinaca · Dasyatispora levantinae gen. et sp. nov.

\section{INTRODUCTION}

The Microsporidia are a group of obligate, eukaryotic, intracellular spore-forming parasites that infect a wide range of host cells and tissue types. These eukaryotic parasites comprise dozens of genera and hundreds of species, invading virtually all major animal groups (Lom 2002). The currently available molecular genetic evidence suggests that the Microsporidia are related to the Zygomycota (Fungi) (Keeling et al. 2000, Tanabe et al. 2002, Lee et al.
2008). In fish, about 100 species belonging to 17 genera, including 93 unidentified species provisionally classified within the genus Microsporidium Balbiani, 1884, have been recorded (Lom 2008). Fish microsporidia typically possess simple life cycles (merogony and sporogony) and a direct transmission (Lom \& Nilsen 2003), although small crustaceans may act as paratenic or intermediate hosts in some fish (see Moodie 2005). Apart from a handful of species belonging to the genus Pleistophora Gurley, 1893 that also infect reptiles and amphibians, microsporidian 
genera that infect fish are not known from other host groups (Lom \& Nilsen 2003).

In the present study, we report a microsporidian infection in a Mediterranean stingray which produces significant pathology, presenting unique observations of this parasite group in an elasmobranch host.

\section{MATERIALS AND METHODS}

Two fishery research campaigns were carried out during May 2008 and July 2009 in Iskenderun Bay, Turkey $\left(36^{\circ} 37^{\prime} \mathrm{N}, 36^{\circ} 07^{\prime} \mathrm{E}\right)$. The study area is located in the far northeast corner of the eastern Mediterranean's Levant basin (Fig. 1). This shallow, $60 \times 35 \mathrm{~km}$ embayment is almost rectangular in shape, covering a surface area of approximately $3755 \mathrm{~km}^{2}$ and is surrounded by a coastline of $\sim 280 \mathrm{~km}$. The average depth is about $70 \mathrm{~m}$, reaching a maximum of about $100 \mathrm{~m}$ (Avşar 1996). The deep bottom areas are covered mainly with silty clays and in the shallower depths $(<45)$ with silty sands (Avşar et al. 2001). Rajiform fish documented from the area include 15 species (Basusta \& Erdem 2000, Turan 2008). Dasyatis pastinaca is a common stingray in the area.

In 2008, several specimens of Dasyatis pastinaca were observed to possess massive tumor-like protuberances on the dorsal surface of the disc (see Fig. 3b). The lesions were large and conspicuous, and representative tissue samples were taken. The lesions were identified as being caused by a microsporidian. In 2009, we encountered the same condition in individuals of $D$. pastinaca caught in the same region, and additional data and material were collected for analysis.

Procedures. Fish were collected by otter trawls with $40 \mathrm{~mm}$ mesh size at the cod end. The duration of each

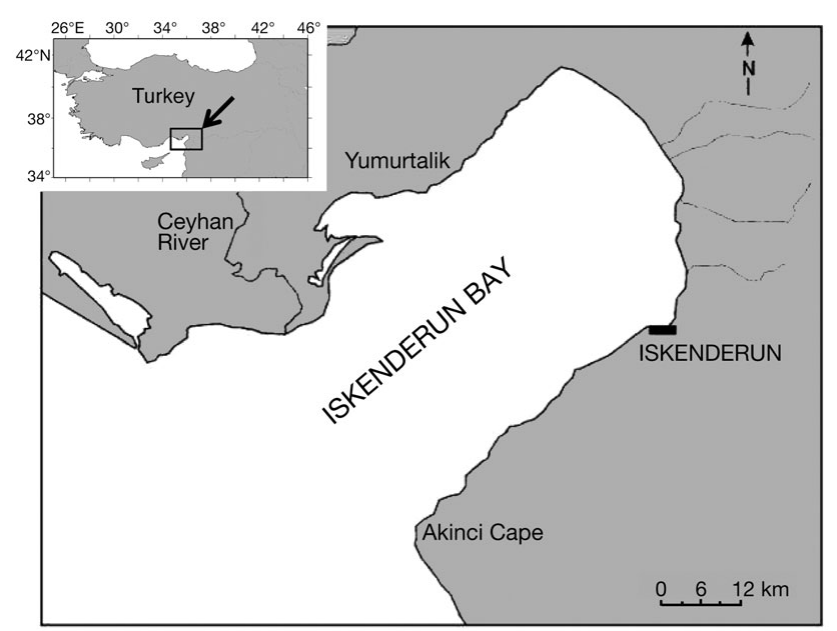

Fig. 1. Study area, Iskenderun Bay, Turkey trawl session was $1 \mathrm{~h}$ and the depth was 20 to $40 \mathrm{~m}$. Upon capture, specimens of Dasyatis pastinaca were placed on crushed ice and refrigerated. After reaching the laboratory, each fish was examined externally, weighed and its disc width was measured. Individuals with external lesions were noted. Three infected individuals and 3 normal-appearing individuals were dissected and their internal organs were examined thoroughly. Small bits of normal and infected muscle tissue were fixed in formalin for $48 \mathrm{~h}$, rinsed and stored in $70 \%$ ethanol for subsequent JB4 methacrylate resin histology processing.

For electron microcopy, small pieces of infected tissue were placed in $2.5 \%$ glutaraldehyde in $0.1 \mathrm{M}$ sodium cacodylate buffer. Samples of the yellowishwhite substance from the lesions containing the parasites were placed in $70 \%$ ethanol for genetic analysis.

Light and electron microscopy. Fresh smears of the microsporidian were air-dried, fixed in absolute methyl alcohol and stained with Giemsa and Gram stain. Light micrographs were taken with an Olympus 4040 camera mounted on Olympus phase contrast and Nomarski interference microscopes.

For histological examination, 10\% buffered neutral formalin-fixed infected tissue was dehydrated and embedded in JB4 blocks, according to the procedure described in Lulham (1979). Three and $4 \mu \mathrm{m}$ sections were stained with hematoxylin and eosin or Gram stain.

For transmission electron microscopy (TEM), infected muscle bits fixed in $2.5 \%$ glutaraldehyde in $0.1 \mathrm{M}$ cacodylate buffer were post-fixed with osmium tetroxide, stained en-bloc with uranyl acetate, and embedded in Agar-100 resin blocks. Thin-sections were cut with a diamond knife on a LKB ultratome III, stained with lead-citrate and mounted on copper grids. The grids were examined in a Jeol 100CXII transmission electron microscope at $60 \mathrm{KV}$.

For scanning electron microscopy (SEM), material fixed in $2.5 \%$ glutaraldehyde in $0.1 \mathrm{M}$ cacodylate buffer was dehydrated in a graded ethanol series and critical point-dried, mounted on stubs, gold-coated and observed in a Jeol JSM 890A scanning electron microscope.

DNA extraction and amplification. A small piece of infected tissue preserved in $70 \%$ ethanol was homogenized with $500 \mu \mathrm{l}$ TNES-urea buffer (Asahida et al. $1996)$ and $12.5 \mu \mathrm{l}$ of proteinase $\mathrm{K}(20 \mathrm{mg} / \mathrm{ml})$ for $3 \mathrm{~h}$ at $37^{\circ} \mathrm{C}$. Following homogenization, DNA was extracted using a standard phenol-chloroform protocol, followed by ethanol-sodium acetate precipitation. A 1825 bp fragment encompassing the partial small subunit rRNA gene, the complete internal transcribed spacer and the $5^{\prime}$-end of the large subunit rRNA gene was obtained by the sequencing of 2 PCR fragments sharing a $282 \mathrm{bp}$ overlap. The first fragment (1406 bp) was 
amplified with the primers 530f-580r (Vossbrinck et al. 1993). The second fragment (701 bp) was located 5' upstream to the 530f-580r sequence. It was amplified with 2 novel primers DAS-24f and DAS-756r. The primer DAS-24f (5'-TGG ATG CTA GTC TCA TAG GTT AGG-3') was designed based on Ovipleistophora and Heterosporis sequence. The primer DAS-756 (5'CAA TTT CTC TTC CGC GGC GCA-3') was designed based on the sequence obtained with the primers 530f-580r. The amplified fragments were directly sequenced on both strands with an ABI PRISM 3100 genetic analyser (Applied Biosystems) using the PCR primers as well as the internal primers 600f, 280r and 800f (Vossbrinck et al. 1993). To complete the sequence on both strands, 3 new specific primers, DAS-565f (5'-ACT ACA GTG GTC ACA GAA AGG AGA GTC TAC-3'), DAS-680r (5'-GTC TTA ATG AGC CCG CGA TTA CTA G-3') and DAS-563r (5'-TAA GGA GCG TTT TGG GGC CAG GG-3') were designed based on the preliminary sequence obtained. The sequence was submitted to GenBank under the accession number GU183263.

Phylogenetic analysis. Preliminary analysis conducted using a large taxon sampling representative of Microsporidia diversity (data not shown) indicated that the sequence of the Dasyatis pastinaca parasite belongs to the class Marinosporidia or Clade III (sensu Vossbrinck \& Debrunner-Vossbrinck 2005). Consequently, the ingroup of our rDNA data set consisted of the Clade III sequences used in the analysis presented by Vossbrinck \& Debrunner-Vossbrinck (2005), as well as all Clade III sequences available in GenBank that were related to the $D$. pastinaca parasite sequence. To identify these related sequences, a MegaBLAST search (www.ncbi.nlm.nih.gov/blast) was conducted using default parameters and our new parasite sequence as query. The outgroup consisted of slow evolving representatives of each of the 4 other microsporidan clades.

Sequence alignment was conducted using the LINS-i algorithm, as implemented in MAFFT 6 (Katoh et al. 2005). Poorly aligned positions of the alignment were excluded using the online version of the program Gblocks 0.91b (Castresana 2000) with the less stringent parameter options. In addition, positions having more than $25 \%$ missing data were removed. The resulting alignment included 69 species and 1172 unambiguously aligned positions, out of which 635 were parsimony informative, 163 were variable and parsimony-uninformative, and 374 were constant.

Phylogenetic trees were reconstructed using both Bayesian and maximum likelihood (ML) approaches. Bayesian analysis was performed under the GTR-CAT model using the program PhyloBayes 3 (Lartillot et al. 2009). This model was chosen since it is the most reli- able model of sequence evolution currently available (Baurain et al. 2007, Lartillot et al. 2007). Two independent chains were run for 24000 cycles ( 2 740000 generations), saving trees every 10 cycles and discarding trees from the first 6000 cycles as burn-in. The maximum difference observed across all bipartitions was 0.04 and the average difference was 0.001 , which indicates a good run according to the PhyloBayes manual. Posterior probabilities (PP) provide branch support at each node. ML analysis was performed with the program RAxML 7.0.4 (Stamatakis 2006), using the GTR + $\Gamma+$ I model of sequence evolution. This model was determined as the best evolutionary model for our data set using the program Modeltest 3.7 (Posada \& Crandall 1998). The $\alpha$ parameter was estimated to be 0.52 and the proportion of invariable sites was 0.09 . The nonparametric bootstrap method was used to assess ML branch support.

\section{RESULTS}

A total of 366 individuals of 9 species of rajiform elasmobranchs were captured in the July 2009 sampling campaign at Iskenderun Bay. These included Dasyatis pastinaca (n = 143), D. chrysonota (131), Rhinobatus cemiculus (41), Gymnura altavela (35), Rhinoptera marginata (9), Raja miraletus (4), Himantura uarnak (1), Pteromylaeus bovinus (1) and Torpedo marmorata (1).

All species of skates and rays were externally examined for gross lesions. Tumor-like protuberances on the body surface, in some cases highly conspicuous, were observed only in Dasyatis pastinaca. The condition was noted in 30 of 143 (21\% prevalence) individuals examined (Fig. 2). No lesions were observed in the internal organs.

\section{Gross pathology}

The earliest clinical signs of infection were whitish subcutaneous spindle-shaped inclusions on the stingray's dorsal surface (Fig. 3b,c). These lesions were offwhite in color, measuring approximately 2 to $3 \mathrm{~mm}$ in width and 7 to $10 \mathrm{~mm}$ in length and as a rule aligned with the adjacent muscle fibers, oriented perpendicular to the disc margin and often located near the fin edge. More advanced stage lesions appeared as ovoid tumor-like masses covered with normal-appearing skin (Fig. 3a,c,d). In heavily infected individuals at an advanced stage of infection, such growths were $>10 \mathrm{~cm}$ and often coalesced to produce deformed masses. The lesions were in general arranged in a radial configuration, much like the spokes of a wheel (Fig. 3b). 


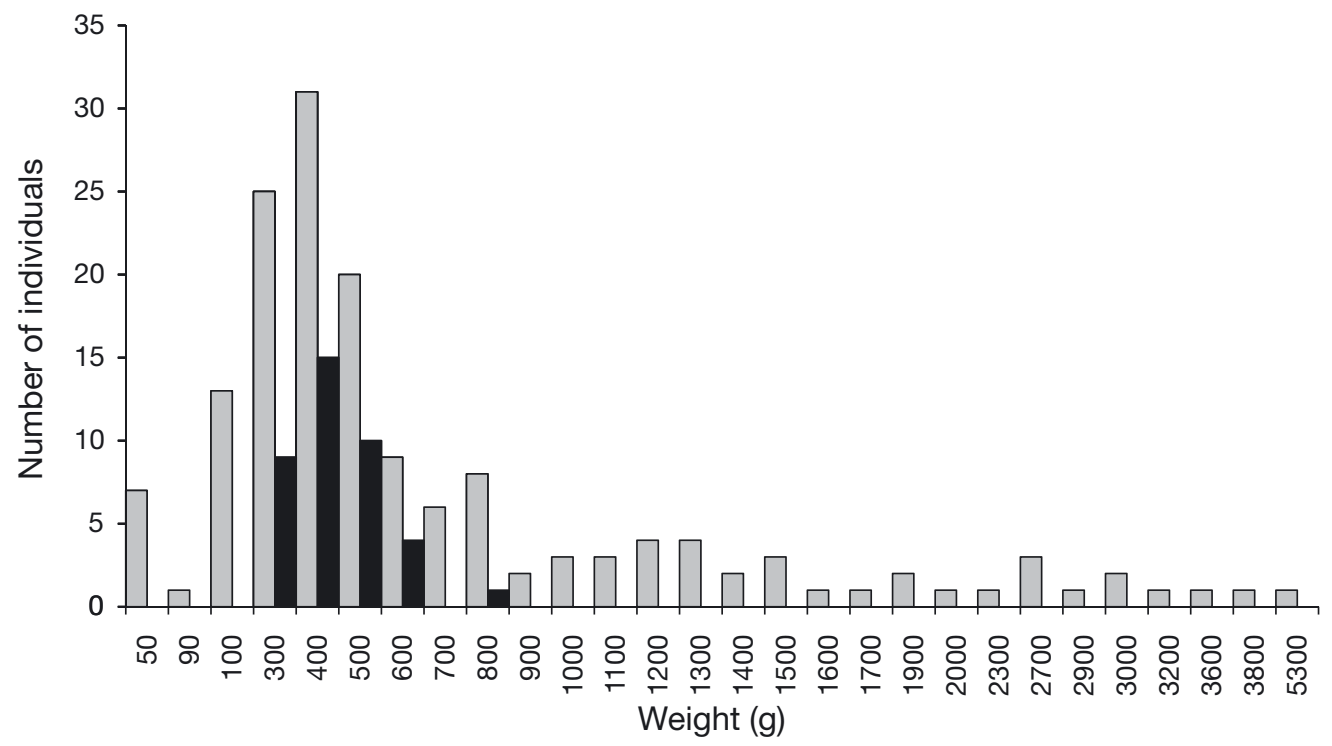

Fig. 2. Dasyatis pastinaca. Prevalence of Dasyatispora levantinae gen. et sp. nov.-infected (black bars) and non-infected (grey bars) individuals amongst the total trawl samples collected in July 2009

The content of the lesions was a whitish-yellow, caseous substance (Fig. 3e,f). Upon microscopical examination, this material was found to contain numerous spherical to ellipsoid sporophorous vesicles (SPVs), each measuring 30 to $40 \mu \mathrm{m}$ in diameter and containing stages of the parasite (Fig. $4 \mathrm{a}, \mathrm{b}$ ). Each SPV contained 160 to 200 spores 3.8 to $4.3 \mu \mathrm{m}$ in length and 2.6 to $2.8 \mu \mathrm{m}$ in width (Fig. $4 \mathrm{c}-\mathrm{e}$ ). In histological sections, the parasite stages-meronts, sporonts, sporoblasts and spores - appeared to develop synchronously in each individual SPV (Fig. 5a-j).

\section{Distribution of the parasite by weight class}

Analysis of the weight distribution of the common stingray Dasyatis pastinaca samples indicated that clinical symptoms resulting from Dasyatispora levantinae gen. et sp. nov. infection became initially visible when the fish were approximately $300 \mathrm{~g}$ in weight. No evidence of infection was observed in any of the individuals weighing $>800 \mathrm{~g}$. Ostensibly healthy individuals with no physical signs of infection weighed up to $5400 \mathrm{~g}$.

\section{Ultrastructure}

With SEM, Dasyatispora levantinae gen. et sp. nov. SPVs could be seen as slightly flattened spheres, measuring approximately $30 \mu \mathrm{m}$ (Fig. 4b). Spores were somewhat elongated and oval-shaped with a smooth outer surface (Fig. 4e).
In TEM sections, multinucleate meronts were observed within SPVs (Fig 6a). SPVs containing groups of uninucleate meronts were also observed (Fig. 6b). Young sporoblasts with an early, primordial polar tube and anchoring disc were observed (Fig. 4c,d). In crosssections, the concentric layers of the isofilar polar tube were seen in immature spores (Fig. 6f,g), in some of which the coils were slightly disorganized and appeared in 2 rows (Fig. 6g). The anchoring disc and posterior vacuole were clearly observed in immature spores. The spore wall displayed the typical double exospore and endospore layers (Fig. 6c-e). The polar tube was isofilar and arranged in 9 (sometimes up to 12) coils (Fig. 6f). Mature spores did not fix well and displayed various degrees of degeneration, indicating a resistant, impermeable spore wall (Fig. 6e).

\section{Histopathology}

In histological sections, normal-appearing muscle tissue was packed with islets of SPVs. The microsporidian proliferated inside the intact muscle, destroying and replacing it while causing liquefaction and degradation of the host cell cytoplasm. The muscle cell nuclei became hypertrophic and developed prominent nucleoli (Fig. 7a). The connective tissue surrounding foci of infected muscle displayed various degrees of hyperplasia. Normal-appearing, intact muscle adjoined areas of infected muscle. In some cases, hyaline degeneration of such muscle was observed (Fig. 7b), possibly as a result of pressure exerted by the adjacent swollen lesions. By and large, the host immune reac- 


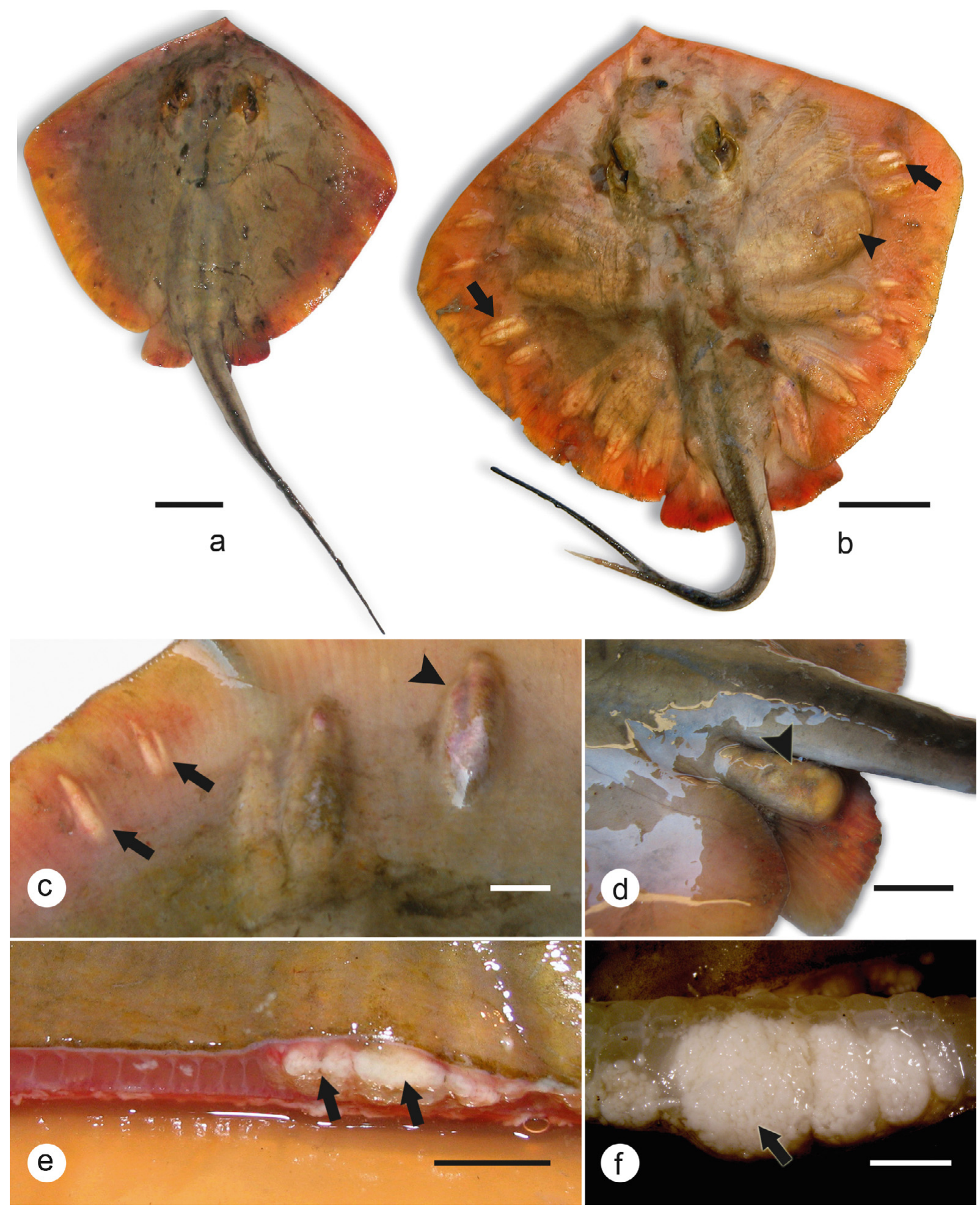

Fig. 3. Dasyatis pastinaca. (a) Uninfected common stingray (scale bar $=5 \mathrm{~cm}$ ). (b) Individual heavily infected with Dasyatispora levantinae gen. et sp. nov., showing microsporidian-induced disfigurement due to numerous protuberances, early lesions (arrows) and advanced stage (arrowhead) (scale bar $=5 \mathrm{~cm}$ ). (c) Magnification of early stage (arrows) and a more advanced lesion (arrowhead) (scale bar $=1 \mathrm{~cm}$ ). (d) Advanced tumor-like protuberance (arrowhead) situated near the base of the caudal peduncle (scale bar $=5 \mathrm{~cm}$ ). (e) Cross-section through fin region with early lesions, showing a whitish-yellow substance containing sporophorous vesicles and host cellular debris (arrows) (scale bar $=1 \mathrm{~cm}$ ). (f) Cross-section through advanced tumor-like lesion, showing whitish yellow substance (arrow) (scale bar $=1 \mathrm{~cm}$ ) 


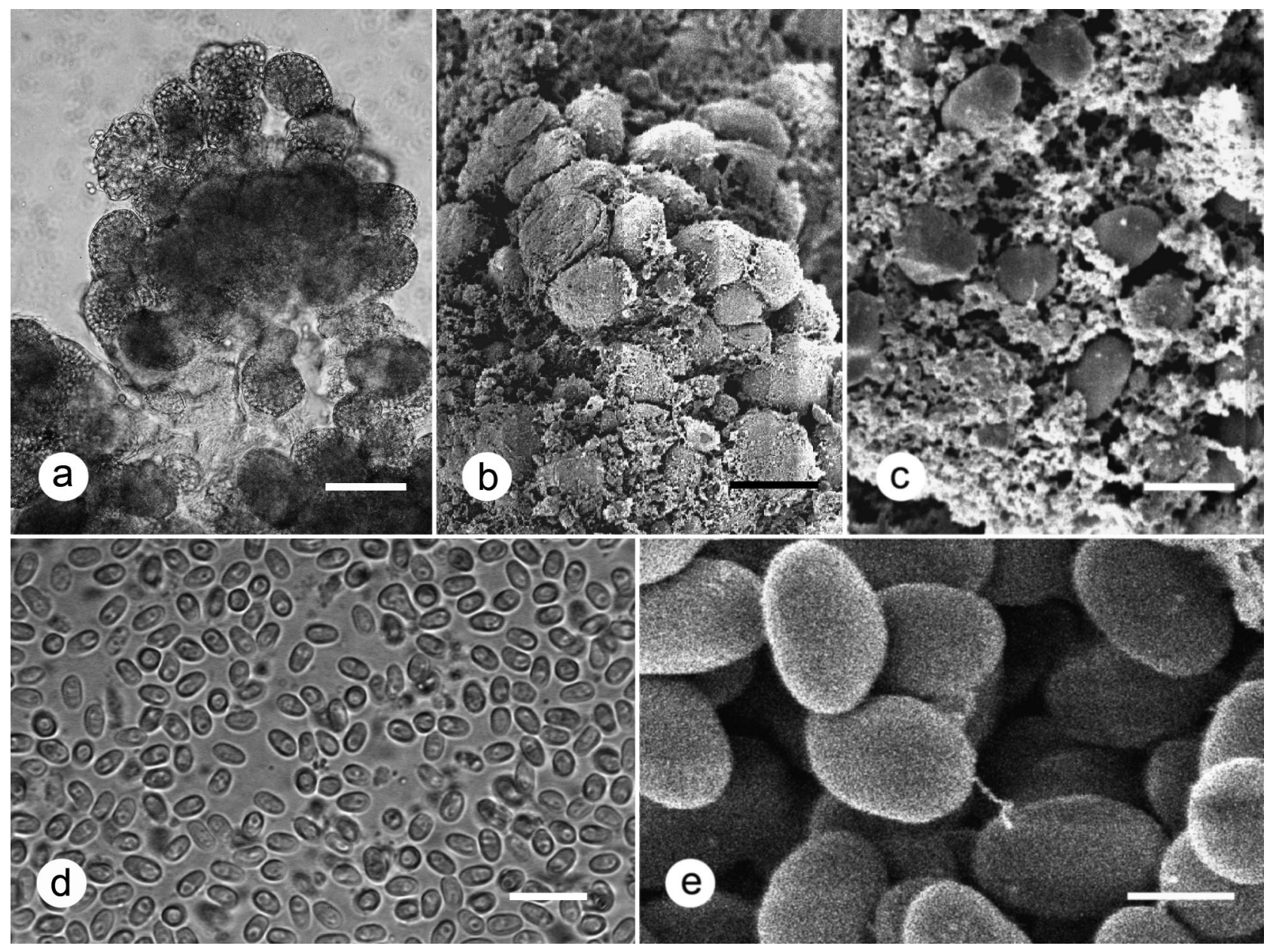

Fig. 4. Dasyatispora levantinae gen. et sp. nov. (a) Sporophorous vesicles (SPVs) (formalin-fixed; scale bar $=30 \mu \mathrm{m}$ ). (b) SPVs embedded in host cellular debris (scanning electron microscopy, SEM; scale bar $=30 \mu \mathrm{m}$ ). (c) Spores surrounded by cellular debris $(\mathrm{SEM}$; scale bar $=5 \mu \mathrm{m})$. (d) Formalin-fixed spores (Nomarski interference microscopy; scale bar $=5 \mu \mathrm{m})$. (e) Spores $(\mathrm{SEM}$; scale bar $=2 \mu \mathrm{m})$

tion to the intact SPVs involved infiltration of leukocytes in the myoseptal connective tissue and muscle surrounding the microsporidian parasite islets (Fig. $7 \mathrm{C}$ ). In areas where free spores were released from disrupted SPVs, the parasite mass was invaded by scores of migratory phagocytic cells, forming a granulomatous zone packed with degraded muscle debris and spores (Fig. 7d). With TEM, spores were observed dispersed freely as well as within macrophages (Fig. 7e,f).

\section{Molecular phylogenetic inferences}

The phylogenetic trees reconstructed with the Bayesian approaches (Fig. 8) and under the ML criterion only differed in the positioning of weakly supported nodes present at the base of Clade III. These trees also agree with Vossbrinck \& Debrunner-
Vossbrinck (2005) maximum parsimony inferences. The phylogenetic analysis clustered with maximal support $(\mathrm{BP}=100, \mathrm{PP}=1.0)$ of the sequence of the Dasyatis pastinaca parasite together with the genera Heterosporis Schubert, 1969 and Ovipleistophora Pekkarinen, Lom \& Nilsen, 2002. Within this clade both Heterosporis (BP $=100, \mathrm{PP}=1.0$ ) and Ovipleistophora $(\mathrm{BP}=100, \mathrm{PP}=1.0)$ genera were found to be monophyletic.

\section{DISCUSSION}

The present study reports on a pathogenic microsporidian infection in an elasmobranch. Only one previous record of a microsporidian infecting a cartilaginous fish has been documented: a cyst-producing microsporidian from the muscle of leopard sharks kept in the Baltimore Public Aquarium (Garner et al. 1998). 




Fig. 5. Dasyatispora levantinae gen. et sp. nov. (a-h) Merogony and sporogony stages of development in sporophorous vesicles (SPVs). (a, b) Multinucleate meront (Giemsa stained; scale bar $=20 \mu \mathrm{m}$ ); (c-e) multinucleate meronts while actively dividing; (f-h) sporont and sporoblast stages. (i) Early (arrow) and late (arrowhead) sporoblasts. (j) Section through infected host muscle showing different stages of development of SPVs: M: young meronts; MN: multinucleate meronts; SN: sporonts; SB: sporoblasts; 


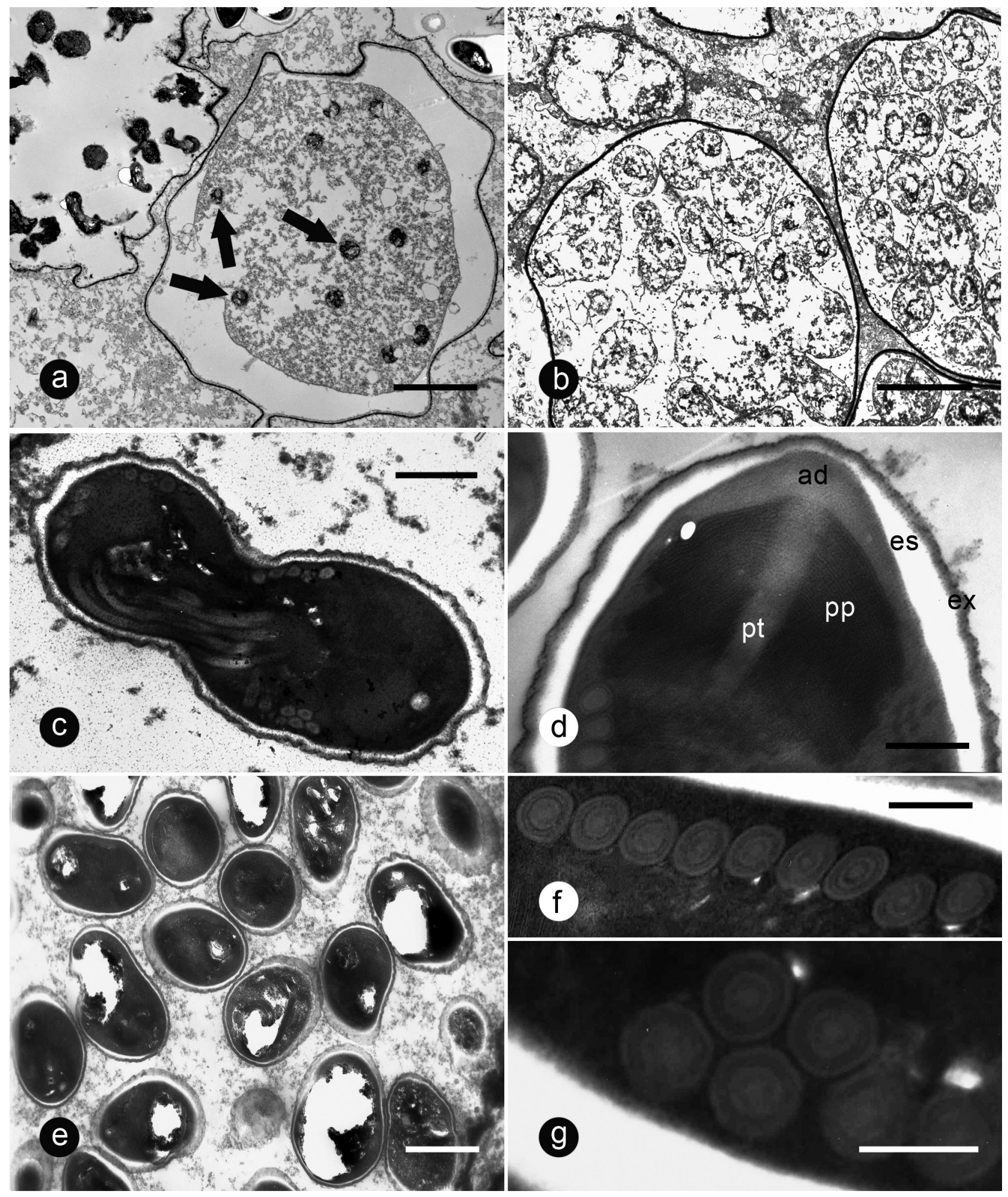

Fig. 6. Dasyatispora levantinae gen. et sp. nov. Transmission electron microscopy. (a) Single, multinucleate meront in a sporophorous vesicle (SPV); nuclei are arrowed (scale bar $=10 \mu \mathrm{m})$. (b) Numerous uninucleate meronts in SPVs (scale bar = $10 \mu \mathrm{m}$ ). (c) Dividing sporoblast; note primordial polar tube (scale bar $=1 \mu \mathrm{m}$ ). (d) Sporoblast showing polar tube connection with the anchoring disc (scale bar $=1 \mu \mathrm{m})$ : ad = anchoring disc; es = endospore; $\mathrm{ex}=$ exospore $; \mathrm{pp}=$ polaroplast $; \mathrm{pt}=$ polar tube. (e) Mature spores in SPV (scale bar $=2 \mu \mathrm{m}$ ). (f) Cross-section with concentric layers seen in polar filament of maturing spore (scale bar $=500 \mathrm{~nm}) .(\mathrm{g})$ High magnification through 2 rows of a slightly disorganized configuration of polar tube (scale bar $=500 \mathrm{~nm}$ ) 


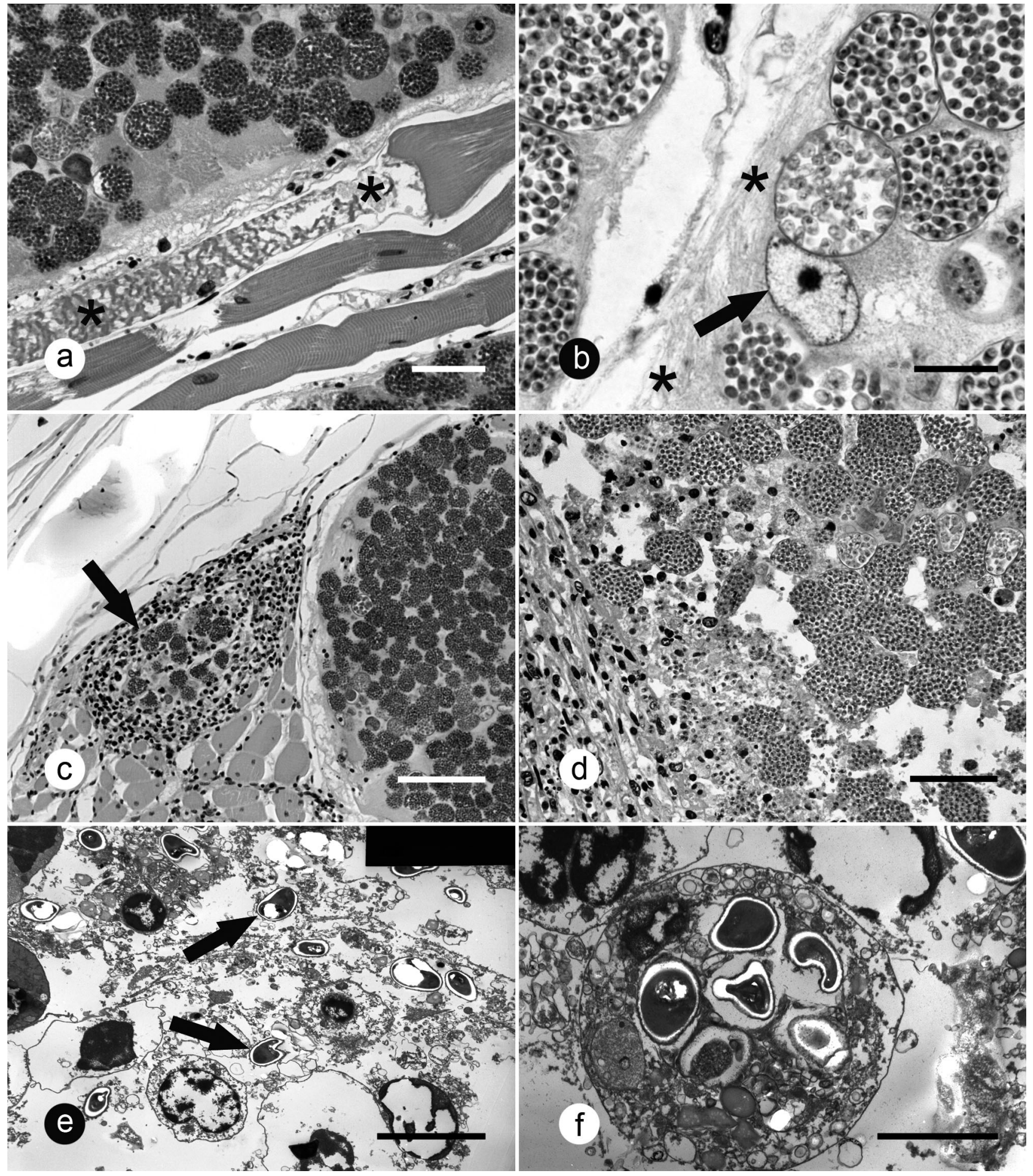

Fig. 7. Dasyatis pastinaca infected by Dasyatispora levantinae gen. et sp. nov. (a-d) Histological sections through muscle (H\&E stained). (a) Myoseptal region of muscle lesion with developing $D$. levantinae gen. et sp. nov., displaying apparently normal muscle as well as muscle undergoing hyaline degeneration (asterisks) (scale bar $=50 \mu \mathrm{m}$ ); (b) developing $D$. levantinae gen. et sp. nov. stages within degraded muscle tissue (asterisks), with hypertrophic host cell nucleus with prominent nucleolus (arrow) (scale bar $=20 \mu \mathrm{m}$ ); (c) granulomatous area (arrow) located at the periphery of a muscle lesion (scale bar $=100 \mu \mathrm{m}) ;(\mathrm{d})$ massive phagocyte and lymphocyte infiltration in region rich with free spores liberated from disrupted SPVs (scale bar $=50 \mu \mathrm{m})$. (e) TEM of similar region, showing free spores (arrows) and host immune cells (scale bar $=10 \mu \mathrm{m}$ ). (f) $D$. levantinae gen. et sp. nov. spores ingested by a phagocyte (scale bar $=5 \mu \mathrm{m}$ ) 


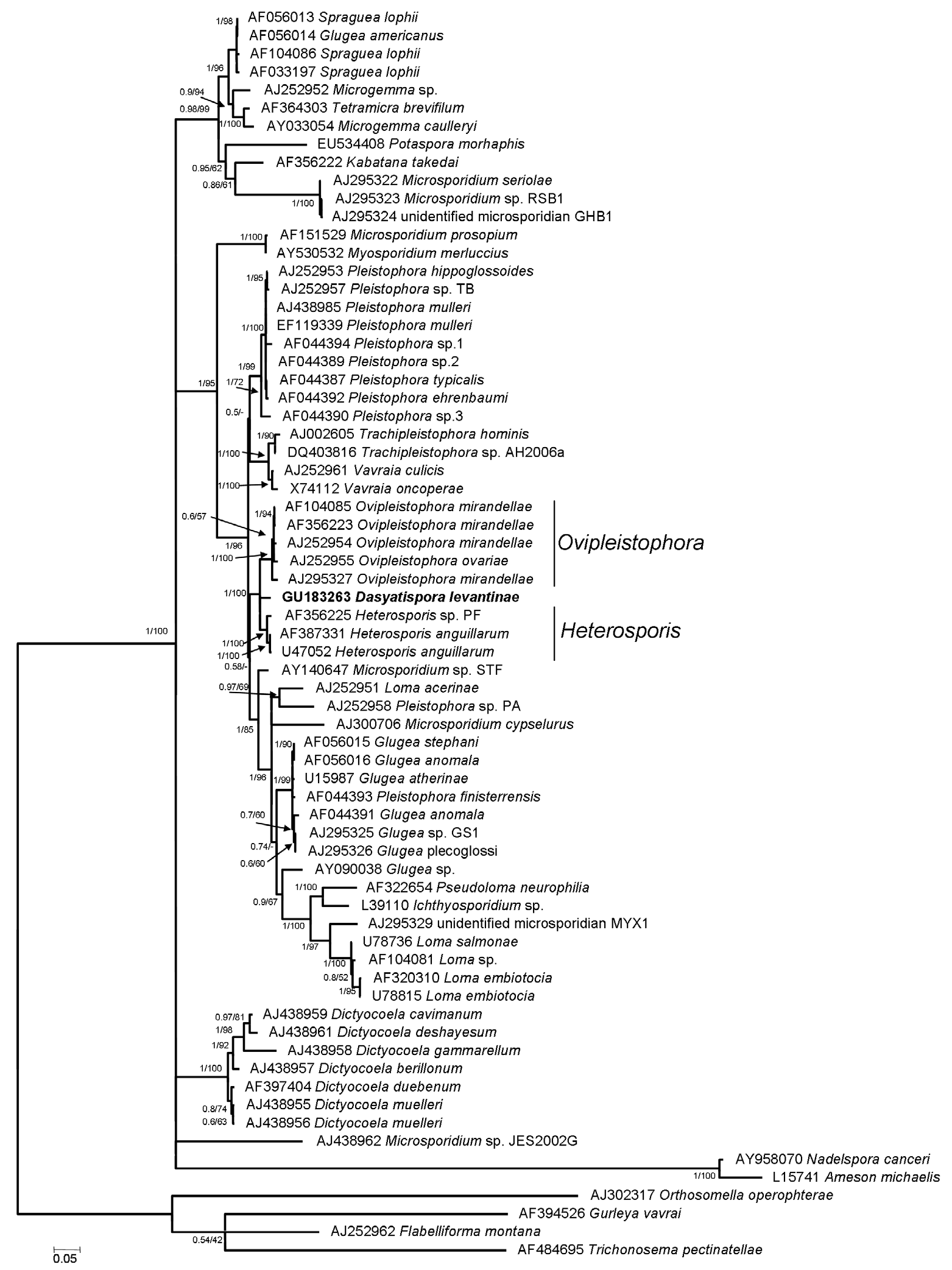

Fig. 8. Bayesian tree obtained from the analysis of the rDNA sequences under the GTR-CAT model of sequence evolution. For each node the Bayesian posterior probabilities and the maximum likelihood (ML) bootstrap percentage are given at the left and right of the slash, respectively. -: a node that was not observed in the ML analysis. Sequences are indicated by their GenBank accession number, followed by the organism name. The newly described microsporidian sequence is indicated in bold. Only nodes with posterior probabilities larger than 0.5 are presented 
The species was not described and is included in a list of unidentified microsporidians of fish compiled by Lom (2002).

The presently studied parasite species was found only in one species, Dasyatis pastinaca, at a relatively high $(21 \%)$ prevalence, while no comparable lesions were noted in any of the other rajiform species, including the congener D. chrysonota, sampled concurrently. It displays a high affinity to trunk muscle myomeres and was not found in any of the external or internal organs. We are unaware of a microsporidian in the eastern Mediterranean that induces comparable muscle lesions in its fish host.

\section{Parasite effect on the host}

As the infection progresses, SPVs packed with ripe spores gradually fill the target (muscle) cell cytoplasm. Normal stingray myocytes infected with the microsporidian are overwhelmed and functional muscle tissue is replaced by agglomerations of microsporidian spores and increasing amounts of degenerative cell debris. This produces engorgement and exerts pressure on surrounding intact tissue, probably inducing the observed thickening of the surrounding connective tissue. Eventually, SPVs will rupture and antigens of parasite origin will stimulate a host reaction, manifested by infiltration of lymphocytes and various types of phagocytic cells. Such an immune response has been described by Dyková \& Lom (1980) as characterizing Pleistophora ehrenbaumi and P. macrozoarcides, both of which produce lesions in their teleost hosts that are strikingly reminiscent to those observed in the common stingray. This type of immune response is known in other microsporidian infections as well (see Pulsford \& Matthews 1991). We observed phagocytosis of free spores, but considering their sheer numbers, the efficiency of such immune activity seemed quite ineffective.

The efficacy of the immune response in parasitehost systems is known to modulate with time, depending on fecundity of the parasite, condition of the host and the environment. In teleosts, cells infected with non-xenoma-producing species of microsporidia, as is the present case, typically display regressive changes (atrophy, degeneration and necrosis) towards the final stages of the infection (see Dyková 2006). Teleost fish humoral and cellular activities are well known to be temperature dependent (Van Muiswinkel \& VervoornVan Der Wal 2006). While relatively little is known on the immune system of elasmobranchs, the efficacy of the immune reaction of the stingray host would likely increase with rising summer seawater temperatures in Iskenderun Bay. At the same time, the development of microsporidian infections is also temperature depen- dent (Olson 1981, Becker \& Speare 2004), and the proliferation of the stingray microsporidian could also be expected to accelerate at higher water temperatures.

Parasite damage to host vital organs may also significantly impair normal function (Ralphs \& Matthews 1986). Microsporidia can harm their hosts in a number of ways, including destruction of tissues, retarded growth, disfigurement, debilitation, crippling and even death (Lom 2008). We may assume that in the demersal common stingray, when the skin overlying a swelling is breached and the lesion ruptures, oozing whitishyellow substance containing SPVs and spore masses from the wound (see Fig. 3f) are likely to attract benthic fish and invertebrates, which could exacerbate the damage. In addition, exposure and ingress of ambient seawater would probably facilitate bacterial contamination, further compromising the host. Individuals affected by advanced stage infections involving multiple lesions may be expected to experience additional detrimental effects. Reduced flexibility of the disc muscles would probably impair swimming and burrowing abilities, consequently affecting foraging success, physiological condition and vulnerability to predation. Analysis of the stingray population structure indicates that individuals up to $300 \mathrm{~g}$ display no physical signs of the disease. Apparently healthy individuals reached weights of $5400 \mathrm{~g}$, while infected individuals larger than roughly $900 \mathrm{~g}(\sim 30 \mathrm{~cm}$ disc width) were not present in the samples, which could suggest that Dasyatis pastinaca populations in Iskenderun Bay are controlled, at least in part, by parasite-induced stunting and/or mortality. It is noteworthy that in salmon, juvenile host individuals have been shown to be more likely to suffer mortality than adults as a result of Loma salmonis infection (Shaw \& Kent 1999).

\section{Description: Dasyatispora levantinae gen. et sp. nov.}

\section{General diagnosis}

Macroscopic lesions varying from 2-3 $\mathrm{mm}$ to $11 \mathrm{~cm}$ extended throughout trunk musculature of Dasyatis pastinaca collected at Iskenderun Bay, Turkey. The lesion border was clearly demarcated from adjoining healthy muscle. Wet mounts of lesion material (immersion, 1000×) reveal ovoid spores.

The microsporidian was determined within the Marinosporidia or Clade III (sensu Vossbrinck \& Debrunner-Vossbrinck 2005) containing mostly parasites of marine hosts. Within this clade, the position of the new microsporidian relative to Heterosporis spp. and Ovipleistophora spp. could not be resolved. The new sequence shows 7.8 to $11.7 \%$ sequence divergence (of which 1.9 to $3.4 \%$ is due to indels) when compared 
with Heterosporis spp. sequences, and 8 to $10.8 \%$ sequence divergence (of which 1 to $1.3 \%$ is due to indels) when compared with Ovipleistophora spp. sequences. The number of base pairs of rDNA analyzed ranged between 1194 to 1852 due to length variation among the Heterosporis spp. and Ovipleistophora spp. sequences available in GenBank. These divergence values exceed that within other microsporidian species, and are in the range of divergence observed between closely related genera.

\section{Taxonomic summary}

Genus: Dasyatispora.

Diagnosis: uni-nucleate throughout developmental cycle. Parasites of muscle. Meronts, sporonts, sporoblasts and spores develop in sporophorous vesicles; sporophorocyst absent; spore dimorphism absent. Parasites of batoid elasmobranchs.

Species: Dasyatispora levantinae. Spore dimensions (formalin fixed, in $\mu \mathrm{m}$ ): $4.0 \pm 0.2 \times 2.7 \pm 0.1$; range: $3.8-4.3$ to $2.6-2.8(\mathrm{~N}=25)$. Sporophorous vesicle dimensions: $38.6 \pm 5.5 \times 30.3 \pm 3.6$; range: 29.8 to 55.6 $(\mathrm{N}=25)$. Number of spores per SPV: 160 to 200.

Type host: common stingray Dasyatis pastinaca (Linnaeus, 1758) (Dasyatidae).

Site of infection: skeletal musculature.

Type locality: Iskenderun Bay, Mediterranean Sea, Turkey (36 $\left.37^{\prime} \mathrm{N}, 36^{\circ} 07^{\prime} \mathrm{E}\right)$.

Prevalence: 30 of 143 (21\%) common stingrays were visibly infected.

Holotype: heavily infected muscle tissue preserved in formalin, deposited at the Tel Aviv University Zoological Museum, Invertebrate Collection, Catalogue no. TAU-MP-1.

Paratypes: JB4 embedded histological sections stained with Giemsa, hematoxylin \& eosin and Lee's stain, catalogue no. TAU-MP-2.

Etymology: the genus denotes the generic name of the host; the species denotes the Levant basin of the eastern Mediterranean.

\section{Remarks}

The inconsistencies between the taxonomic designations based on morphological characters and evolutionary relationships of the phylum Microsporidia, as reflected by the analysis of rDNA, have been addressed by Lom \& Nilsen (2003) and Vossbrinck \& Debrunner-Vossbrinck (2005), who proposed that future taxonomic divisions be based primarily on phylogenetic relatedness as well as considering the significance of habitat and host in major taxonomic divisions.
The presently studied microsporidian does not induce xenomas in its host. Of the 16 currently recognized microsporidian genera in fish (including the collective group Microsporidium) (see Lom 2008), only 5 fit this criterion and do not elicit xenomas, among which is Kabatana Lom, Dyková \& Tonguthai, 2000, a muscle-invading species. However, Kabatana lacks sporophorous vesicles.

In the molecular analyses, our species resolved within Clade III within the Class Marinosporidia of Vossbrinck \& Debrunner-Vossbrinck (2005), parasites of marine hosts. It clusters on a distinct branch together with 3 other species Ovipleistophora mirandellae, $O$. ovariae and Heterosporis anguillarum. Ovipleistophora spp. do not infect muscle, but rather exclusively target fish oocytes (Pekkarinen et al. 2002). The 2 species $O$. mirandellae and $O$. ovariae parasitize freshwater teleosts and display spore dimorphism, i.e. producing both macro- and microspores (Pekkarinen et al. 2002).

Heterosporis anguillarum produces lesions in trunk muscle of the Japanese eel Anguilla japonicum Temminck \& Schlegel, 1846 which are comparable to those observed in Dasyatis pastinaca. However, Dasyatispora levantinae gen. et sp. nov. differs in several attributes from species belonging to the genus Heterosporis. Most importantly, we found no evidence of spore dimorphism, which is a pivotal feature in the genus Heterosporis. While all members of Heterosporis possess spores with a very large posterior vacuole and all develop within an SPV, the number of spores per SPV is significantly larger in D. levantinae gen. et sp. nov. Also, parasite development in Heterosporis takes place within a sporophorocyst, a thick, dense envelope of parasite origin that develops around the meronts, sporonts, sporoblasts and spores. This structure is absent in D. levantinae gen. et sp. nov.

In addition to these differences, all fish hosting known species of Heterosporis and Ovipleistophora inhabit very different habitats in geographically remote regions. H. anguillarum infects the Japanese eel Anguilla japonicum, a catadromous elopomorphan teleost from the Pacific Ocean. $H$. finki Schubert, 1969 and $H$. schuberti Lom, Dyková, Korting \& Klinger, 1989 infect freshwater ornamental cichlid and siluriform hosts, while O. mirandella infects cyprinid hosts of freshwater habitats in Europe and central Asia. Finally, $O$. ovariae infects North American cyprinids. In contrast, Dasyatis pastinaca is a truly marine elasmobranch that inhabits the Mediterranean and eastern Atlantic Ocean.

Several Pleistophora included in our molecular phylogenetic analyses, which clustered in different lineages, display similar developmental features and cause fairly similar lesions to Dasyatispora levantinae 
gen. et sp. nov., which could suggest that this mode of development has evolved independently several times in the Microsporidia. The genus Pleistophora is polyphyletic and includes 25 named species and an additional 7 described as 'sp.' (Lom 2008). Many of these are clearly unrelated to the type species (see Vossbrinck \& Debrunner-Vossbrinck 2005). The number of spores formed per Pleistophora SPV span between 6 and 200, with some species producing heterogenous (micro- and macro-) spores. Meronts are multinucleate and rounded, and all stages have isolated nuclei; the parasite typically proliferates in myocyte cytoplasm, spreading to new host cells and eventually degrading the tissue into bundles of mature spores, creating whitish foci in the muscle tissue.

Positioned on a separate branch within the Marinosporidia, Pleistophora ehrenbaumi Reichenow, 1929 infects the wolffish Anarhichas minor Olafsen, 1772 and A. lupus Linnaeus, 1758 from the Atlantic Ocean, forming brownish needle-like lesions packed with spores in the host trunk muscles. Egidius \& Soleim (1986) found a giant tumor-like swelling in an emaciated individual, and reported a $10 \%$ prevalence of $P$. ehrenbaumi in A. minor populations. Meyer (1952) reported a similar prevalence in populations of $A$. lupus. Pleistophora macrozoarcidis Nigrelli, 1946, whose SSU rDNA sequence is still unavailable, infects the ocean pout Macrozoarces americanus (Bloch \& Schneider, 1801), producing small, white cylinders $0.5 \mathrm{~mm}$ long aligned lengthwise with the trunk muscle fibers. Such parasite foci mature into tumor-like masses up to $8 \mathrm{~cm}$ long that gradually replace healthy muscle tissue with parasite spores. These produce bulges on the body surface. Prevalence of infection increases with host age and size (Sheehy et al. 1974). The pathology induced by this species as described by Nigrelli (1946) is remarkably similar to that caused in Dasyatis pastinaca by Dasyatispora levantinae gen. et sp. nov. Pleistophora-type infections are thought to have a severe prognosis for the host (Dyková \& Lom 1980).

The available morphological and molecular evidence, host phylogeny and host habitat support the placing of this newly discovered microsporidian in a separate genus, which, based on rDNA phylogeny, should be located within the Marinosporidia.

Acknowledgements. We thank K. Gayer, N. Stern, M. Cooper, E. Kalkan, U. Tural, S. Sakinan and B. Colorni for their invaluable help on-board the fishing vessels and in the laboratory. Thanks also to L. Fishelson for his support with the SEM work. Special thanks to C. and S. Kara of Ceyhan Balikçilik, who amiably hosted us at Iskenderun, for access to their fishing vessels and for providing us with laboratory working space in their onshore refrigerated storehouse facility. This research was supported by the Porter School of Environmen- tal Studies at Tel Aviv University with funding from the Italian Ministry of the Environment, Land and Sea, R\&D Project (2008).

\section{LITERATURE CITED}

Asahida T, Kobayashi T, Saitoh K, Nakayama I (1996) Tissue preservation and total DNA extraction from fish stored at ambient temperature using buffers containing high concentration of urea. Fish Sci 62:727-730

Avşar D (1996) Physico-chemical characteristics of the Eastern Mediterranean in relation to distribution of the new Scyphomedusae (Rhopilema nomadica). Turk J Zool 23: 605-616

Avşar N, Meric E, Ergin M (2001) Foraminiferal content of the benthogenic sediments in the Iskenderun Bay. Hacettepe Univ Yerbilimleri 24:97-112 (in Turkish)

Basusta N, Erdem U (2000) A study on the pelagic and demersal fishes of Iskenderun Bay. Turk J Zool 24(Suppl): $1-19$

Baurain D, Brinkmann H, Philippe H (2007) Lack of resolution in the animal phylogeny: Closely spaced cladogeneses or undetected systematic errors? Mol Biol Evol 24:6-9

> Becker JA, Speare DJ (2004) Impact of a water temperature shift on xenoma clearance and recovery time during a Loma salmonae (Microsporidia) infection in rainbow trout Oncorhynchus mykiss. Dis Aquat Org 58:185-191

Castresana J (2000) Selection of conserved blocks from multiple alignments for their use in phylogenetic analysis. Mol Biol Evol 17:540-552

Dyková I (2006) Phylum Microspora. In: Woo PTK (ed) Fish diseases and disorders, Vol 1: protozoan and metazoan infections. CAB International, Wallingford, p 205-229

Dyková I, Lom J (1980) Tissue reactions to microsporidian infections in fish. J Fish Dis 3:265-283

Egidius E, Soleim O (1986) Pleistophora ehrenbaumi, a microsporidian parasite in wolffish, Anarhichas lupus. Bull Eur Assoc Fish Pathol 6:13-15

Garner MM, Miller-Morgan TJ, Brown SR, Reimschuessel R, Poynton SL, Baldwin TJ, Olson RE (1998) Microsporidiosis in leopard sharks. In: Kane AS, Poynton SL (eds) Proc Third Int Symp Aquat Animal Health, Aug 30-Sep 3, 1998, Baltimore, MD, p 145 (Abstract)

Katoh K, Kuma K, Toh H, Miyata T (2005) MAFFT version 5: improvement in accuracy of multiple sequence alignment. Nucleic Acids Res 33:511-518

> Keeling PJ, Luker MA, Palmer JD (2000) Evidence from betatubulin phylogeny that Microsporidia evolved from within the fungi. Mol Biol Evol 17:23-31

Lartillot N, Brinkmann H, Philippe H (2007) Suppression of long-branch attraction artefacts in the animal phylogeny using a site-heterogeneous model. BMC Evol Biol 7 (Suppl 1):S4

> Lartillot N, Lepage T, Blanquart S (2009) PhyloBayes 3: a Bayesian software package for phylogenetic reconstruction and molecular dating. Bioinformatics 25:2286-2288

- Lee SC, Corradi N, Byrnes EJ, Torres-Martinez S, Dietrich FS, Keeling PJ, Heitman J (2008) Microsporidia evolved from ancestral sexual fungi. Curr Biol 18:1675-1679

- Lom J (2002) A catalogue of described genera and species of microsporidians parasitic in fish. Syst Parasitol 53:81-99

Lom J (2008) Microsporidia. In: Eiras JG, Segner H, Wahli T, Kapoor GB (eds) Fish diseases, Vol. 1. Scientific Publishers, Enfield, p 351-395

> Lom J, Nilsen F (2003) Fish Microsporidia: fine structural diversity and phylogeny. Int J Parasitol 33:107-127 
Lulham CN (1979) Glycol methacrylate embedding for light microscopy. J Histotechnol 2:68-71

Meyer A (1952) Veränderung des Fleisches beim Katfish. Fischereiwelt 4:57-58

Moodie E (2005) Microsporidia (microsporans). In: Rohde K (ed) Marine parasitology. CSIRO Publishing, Collingwood, p 30-34

Nigrelli RF (1946) Parasites and diseases of the ocean pout, Macrozoarces americanus. Bull Bingham Oceanogr Collect 9:187-202

Olson RE (1981) Effects of low temperature on the development of the microsporidian Glugea stephani in English sole (Parophrys vetulus). J Wildl Dis 17:559-562

Pekkarinen M, Lom J, Nilsen F (2002) Ovipleistophora gen. n., a new genus for Pleistophora mirandellae-like microsporidia. Dis Aquat Org 48:133-142

Posada D, Crandall KA (1998) MODELTEST: testing the model of DNA substitution. Bioinformatics 14:817-818

Pulsford A, Matthews RA (1991) Macrophages and giant cells associated with a microsporidian parasite causing liquefaction of the skeletal muscle of the Norway pout, Trisopterus esmarkii (Nilsson). J Fish Dis 14:67-78

Ralphs JR, Matthews RA (1986) Hepatic microsporidiosis due to Microgemma hepaticus n. gen., n. sp. in juvenile grey mullet Chelon labrosus. J Fish Dis 9:225-242

Editorial responsibility: Dieter Steinhagen,

Hannover, Germany
Shaw RW, Kent ML (1999) Fish Microsporidia. In: Wittner M, Weiss LM (eds) The Microsporidia and microsporidiosis. ASM Press, Washington, DC, p 447-501

Sheehy DJ, Sissenwine MP, Saila SB (1974) Ocean pout parasites. Mar Fish Rev 36:29-33

Stamatakis A (2006) RAxML-VI-HPC: maximum likelihoodbased phylogenetic analyses with thousands of taxa and mixed models. Bioinformatics 22:2688-2690

Tanabe Z, Watanabe MM, Sugiyama J (2002) Are Microsporidia really related to Fungi? A reappraisal based on additional gene sequences from basal fungi. Mycol Res 106:1380-1391

Turan C (2008) Molecular systematic analyses of Mediterranean skates (Rajiformes). Turk J Zool 32:437-442

Van Muiswinkel WB, Vervoorn-Van Der Wal B (2006) The immune system of fish. In: PTK Woo (ed) Fish diseases and disorders. CAB International, Wallingford, p 678-701

- Vossbrinck CR, Debrunner-Vossbrinck BA (2005) Molecular phylogeny of the Microsporidia: ecological, ultrastructural and taxonomic considerations. Folia Parasitol 52:131-142

Vossbrinck CR, Baker MD, Didier ES, Debrunner-Vossbrinck BA, Shadduck JA (1993) Ribosomal DNA sequences of Encephalitozoon hellem and Encephalitozoon cuniculi: species identification and phylogenetic construction. J Eukaryot Microbiol 40:354-362

Submitted: February 3, 2010; Accepted: June 18, 2010 Proofs received from author(s): July 30, 2010 